ORIGINAL ARTICLE

\title{
Will changes in primary care improve health outcomes? Modelling the impact of financial incentives introduced to improve quality of care in the UK
}

\author{
P McElduff, G Lyratzopoulos, R Edwards, R F Heller, P Shekelle, M Roland
}

Qual Saf Health Care 2004;13:191-197. doi: 10.1136/qshc.2003.007401

See end of article for authors' affiliations

Correspondence to: Dr P McElduff, Evidence for Population Health Unit, University of Manchester, Oxford Road, Manchester M13 9PT, UK; patrick. mcelduff@man.ac.uk

Accepted for publication 10 February 2004

\begin{abstract}
Objectives: To estimate the total health gain from improving the quality of care among patients with cardiovascular disease in line with the quality indicator targets in the new contract for general practitioners (GPs) in the UK.

Design: Statistical modelling, applying population impact measures to estimate cardiovascular health gains from achieving treatment targets in the GP contract, taking into account current levels of treatment and control.

Main outcome measures: Number of events prevented in the population over 5 years applied to a notional general practice population of 10000 .

Results: The greatest health gain in those aged 45-84 years would come from reaching cholesterol reduction targets. This could prevent 15 events in people with coronary heart disease, seven events in those with a history of stroke, and seven events in those with diabetes. Achieving blood pressure control targets in hypertensive patients without the above conditions could prevent 15 cardiovascular events, with further benefits from reducing blood pressure in patients with high blood pressure and coronary heart disease, stroke, or diabetes. Achieving other targets would have smaller impacts because high levels of care are already being achieved or because of the low prevalence of conditions or associated event risk.

Conclusion: It is possible to quantify the health gain to a practice population of achieving quality targets such as those set in the new GP contract. The amount of health gain is sensitive to current quality of care, prevalence of conditions, and risk factors, and to the size of change anticipated. Nevertheless, it appears that significant health gains could result from achieving the proposed quality targets.
\end{abstract}

$M$ anagers of healthcare systems throughout the world are seeking to maximise their effectiveness and cost effectiveness. At the same time there is a drive in many countries for greater accountability from health professionals. The UK government has responded to this by proposing a radical change in the way that general practitioners (GPs) are paid, with a substantial proportion of their income potentially tied to a wide ranging and complex set of quality indicators included in the current ("new") GP contract. ${ }^{1}$

The new GP contract provides financial incentives for the achievement of a set of 76 clinical quality indicators covering 10 disease groups, including coronary heart disease (and left ventricular dysfunction), stroke, hypertension, diabetes, chronic obstructive pulmonary disease, epilepsy, hypothyroidism, cancer, mental health, and asthma. These include the availability of disease registers and standards for the processes of: diagnosis and investigation, referral, clinical monitoring and review; recording and management of risk factors for complications; and treatment and control of risk factors and disease. There are also 56 quality indicators for five organisational and management areas including the quality of systems for managing patient records and information or information technology; methods of communication with patients; training and appraisal of staff; and medicines management. Finally, there are quality indicators for the accessibility of the practice, length of appointment times, and for undertaking and acting on the results of patient surveys. ${ }^{1}$ Between $30 \%$ and $50 \%$ of a GP's income may be dependent on meeting the targets specified in the contract.

The UK is not the first government to introduce a large scale incentive scheme for primary care quality. The
Australian government, for example, now rewards practices that meet accreditation standards relating to use of information technology, provision of after hours care, teaching, and quality of prescribing. ${ }^{2}{ }^{3}$ However, the British proposals are much more extensive and specific.

A systematic review recently examined the level of quality of care delivered by primary care services in the UK, New Zealand and Australia. ${ }^{4}$ Another recent study explored predictors of quality of care in a large number of UK practices. ${ }^{5}$ These studies found wide variation in the quality of care between general practices in the UK. This suggests that there are substantial opportunities to improve health by improving the quality of primary care, at least in some practices. If the financial incentives offered by the contract are successful in producing major changes in clinical practice, significant health gain should result. While GPs are likely to respond to financial incentives aimed at improving quality of care, ${ }^{67}$ there remains an important question as to how much total health gain is likely to result at the practice level. The targets proposed in the contract are challenging. However, there is evidence from diabetic registers and from other quality improvement schemes that achieving these targets is possible. $^{8}$

We have conducted a study with the aim of estimating the potential health benefits that would result if a number of quality indicators included in the current GP contract relating to aspects of cardiovascular disease (CVD) management were to be met. To make the health benefit estimates more meaningful, we have calculated health gain for a hypothetical general practice population of 10000 with the age and sex distribution of England and Wales. The indicator targets were selected on the basis that there was likely to be significant 
health gain from achieving them, and that the health gain could be estimated with reasonable precision using data from clinical trials and large scale observational studies.

\section{METHOD}

We used mathematical modelling that incorporates published data on the effectiveness of interventions and the current rate of performance to estimate the health benefits of increasing the performance of five cardiovascular disease indicators in the new GP contract as applied to a hypothetical general practice population. The five different interventions were:

- aspirin;

- cholesterol lowering treatment;

- hypertension management;

- treatment with angiotensin converting enzyme (ACE) or angiotensin 2 (A2) inhibitors;

- influenza immunisation.

The potential health impact of these indicators relates to the management of coronary heart disease (CHD), stroke, diabetes, CHD and heart failure, hypertension, and cardiovascular disease in general.

\section{Prevalence of disease and risk factor levels}

The prevalences of CHD, stroke, diabetes, and hypertension were estimated from the 1998 Health Survey for England. ${ }^{\prime}$ Our category of "hypertension" excludes people with hypertension who also have diabetes, stroke, or CHD because we estimate the benefit of blood pressure reduction in those groups separately. For heart failure due to left ventricular systolic dysfunction we used prevalence estimates from a recent UK population based epidemiological study. ${ }^{10}$ As the proposed relevant indicator only relates to patients with heart failure due to CHD, we adjusted our prevalence estimates for heart failure using data from a population based study of the aetiology of heart failure. ${ }^{11}$

\section{Proportion of patients eligible for treatment}

The incremental proportion of the population eligible for the intervention ( $\mathrm{P}_{\text {einc }}$ ) equates to the "target" value of the GP quality indicator minus the proportion of patients who are currently receiving treatment. The "target" value only relates to those patients with no contraindication to the treatment.

Data on cholesterol and blood pressure levels were obtained from the 1998 Health Survey for England. ${ }^{9}$ In the absence of timely and accurate data of current treatment levels from population based disease registers, we used a long standing primary care data collection project from Northumberland (Northumberland Morbidity and Epidemiology Data Interchange and Comparison Scheme) which collects data from all 52 practices serving a population of over 300000 and from a population based survey of treatment status. ${ }^{12}{ }^{13}$ As we could not obtain published estimates of the uptake of A2 antagonists we have assumed a ratio of 8.5:1 between uptake of ACE inhibitors and A2 antagonists based on local unpublished data from audit of care of heart failure. ${ }^{14}$ As the proposed indicator for ACE inhibitors and A2 antagonists relates to patients with heart failure and CHD, we assumed that uptake of these drugs in heart failure is independent of CHD status, and used uptake data from a population based survey of treatment status. ${ }^{13}$ The proposed indicators include the uptake of "aspirin, other antiplatelet agents or warfarin" in eligible patients with CHD and stroke. For simplicity, we opted to model only the impact of aspirin treatment. In practice, this represents the great majority of such patients and the contraindication profile (such as predisposition to bleeding) is very similar for all of the above drugs.

\section{Baseline risk estimate}

The baseline risk for cardiovascular events among hypertensive patients and diabetics without a history of CHD, stroke, or heart failure was estimated by calculating the risk for each participant in the 1998 Health Survey of England ${ }^{9}$ using the Framingham equation ${ }^{15}$ and then calculating the mean risk among subjects of a particular sex and age. This implies that a cardiovascular event is defined as per the Framingham study and includes angina pectoris, myocardial infarction, death from CHD, stroke, congestive heart failure, peripheral vascular disease, and death from cardiovascular disease. ${ }^{15}$ The baseline risk for patients with CHD, stroke and heart failure was assumed to be 1.5, 2.0 and 3.5 times, respectively, the risk of those without a history of CHD, stroke and heart failure. For influenza mortality we have used estimates of underlying respiratory and circulatory deaths from US data (as coded influenza deaths underestimate mortality due to influenza). ${ }^{16}{ }^{17}$ Since influenza mortality is greater in those with a chronic disease, we have multiplied these rates by 2.5 as an estimate of the relative risk of influenza mortality among the groups covered in this paper. ${ }^{18-20}$

\section{Relative risk reduction for all cardiovascular events and for all cause mortality}

Data from recently published meta-analyses or, in the absence of meta-analyses, from large randomised controlled trials in the most appropriate populations and settings were used to obtain the estimates of relative risk reduction (RRR) (table 1). For ACE inhibitors and A2 antagonist monotherapy we have assumed a similar effect size. ${ }^{21}$ We used 5 year RRR where published, otherwise we assumed that, despite different follow up periods for many of the trials, the published RRR is time independent and applies to 5 year mortality as well. We have applied RRR estimates to all eligible patients not currently treated, independent of age, sex, and disease stage/severity. This was justified by the observation of such independence for various cardiovascular treatments among treatment subgroups in the randomised controlled trials ${ }^{22-24}$ and by relevant suggestions in the literature..$^{25-27}$ The cardiovascular disease end points in the trials were not defined exactly the same as in the Framingham study but we have assumed that the RRR are similar.

\section{Estimating the number of events prevented}

We have used a previously described method for estimating the benefit to a notional population of increased use of effective treatments. ${ }^{28}$ The calculation involves multiplying the number of patients with the condition who are eligible for treatment by the baseline risk for the adverse event, the estimated RRR associated with the use of the intervention, and the additional proportion of the population treated from an incremental increase in the use of the intervention.

For categorical variables, the number of events prevented in your population (NEPP) by the intervention is calculated as:

$$
\mathrm{NEPP}=\mathrm{n} \times \mathrm{p}_{\mathrm{r}} \times\left(1-\mathrm{c}_{\mathrm{i}}\right) \times \mathrm{p}_{\mathrm{e}} \times \mathrm{P} \times \mathrm{RRR}
$$

where $\mathrm{n}=$ number of people in the practice population $(10000 \times$ proportion in a particular age group in this exercise), $p_{r}=$ prevalence of the disease in the population, $\mathrm{C}_{\mathrm{i}}=$ proportion of patients with a contraindication to the medication, $\mathrm{p}_{\mathrm{e}}=$ proportion of the prevalent population eligible for the intervention, $\mathrm{P}=$ probability of the outcome of interest (baseline risk) during chosen follow up period, and $\mathrm{RRR}=$ relative risk reduction associated with the treatment. 
Table 1 Estimates of relative risk reduction of cardiovascular events and all cause mortality

\begin{tabular}{|c|c|c|}
\hline Disease (intervention) & Outcome & Relative risk reduction (RRR) \\
\hline CHD (aspirin) & Cardiovascular events* & $25 \%^{34}$ \\
\hline $\begin{array}{l}\mathrm{CHD} \text { and HF (ACE inhibitors/A2 } \\
\text { antagonists) }\end{array}$ & $\begin{array}{l}\text { Death or hospitalisation } \\
\text { for HF }\end{array}$ & $26 \%^{24}$ \\
\hline Stroke (aspirin) & Cardiovascular events* & $22 \%^{34}$ \\
\hline CHD (influenza immunization) & Deaths from influenza & $50 \%^{27}$ \\
\hline $\begin{array}{l}\text { Hypertension (antihypertensive } \\
\text { treatment) }\end{array}$ & Cardiovascular events* & $\begin{array}{l}11 \% \text { reduction in } \mathrm{CHD} \text { and } 19 \% \text { reduction } \\
\text { in stroke } \mathrm{s}^{30} \text { per } 2.5 \mathrm{~mm} \mathrm{Hg} \text { reduction in } \\
\text { DBP }\end{array}$ \\
\hline $\begin{array}{l}\text { Hypertension and CHD } \\
\text { (antihypertensive treatment) } \\
\text { Hypertension and stroke } \\
\text { (antihypertensive treatment) } \\
\text { Hypertension and diabetes } \\
\text { (antihypertensive treatment) }\end{array}$ & & \\
\hline $\begin{array}{l}\text { High cholesterol and CHD } \\
\text { (cholesterol lowering treatment) } \\
\text { High cholesterol and stroke } \\
\text { (cholesterol lowering treatment) } \\
\text { High cholesterol and diabetes } \\
\text { (cholesterol lowering treatment) }\end{array}$ & Cardiovascular events* & $\begin{array}{l}10 \% \text { reduction in CVD events per } \\
0.2 \text { mmol// reduction }{ }^{31} 32\end{array}$ \\
\hline
\end{tabular}

We have assumed a risk period of 5 years and a base population of 10000 with the age and sex distribution of England and Wales in $2000 .^{29}$ The risk period of 5 years was chosen because it is in the range suggested for use with the Framingham equations and because it is similar to the mean follow up period for the trials and meta-analyses used to estimate relative risk reductions.

In this paper $p_{\text {einc }}$ is used instead of $p_{e}$ to indicate that we are estimating the effect of an incremental increase in the uptake of the intervention from the current level within a practice to the level specified in the quality indicator targets.

As an example, consider the number of cardiovascular events prevented by the incremental increase in aspirin among men aged 45-64 years. The nominal population of 10000 has 1154 (11.54\%) men aged 45-64 years of which 96 $(8.35 \%)$ have CHD. The target is to increase the use of aspirin to $90 \%$ of those patients who have no contraindication to aspirin. If we assume that $10 \%$ of people have a contraindication, then 87 of the men in this population are candidates for treatment. The current treatment level is $81 \%$ indicating that 70 of them are already treated. This represents an incremental increase in the use of aspirin of $9 \%$ and the NEPP is:

$$
1154 \times 0.0835 \times(1-0.10) \times 0.09 \times 0.128 \times 0.25=0.25
$$

This indicates that increasing the level of treatment with aspirin to $90 \%$ (from $81 \%$ ) among those with no contraindication will prevent 0.25 cardiovascular events in this nominal population of 10000 people during a 5 year period.

The NEPP associated with each intervention was calculated for men and women separately and for age groups 4564 years and $65-84$ years. We have not included people aged less than 45 years or older than 85 years, largely because of the instability of estimates of both treatment uptake and risk factor levels among these age groups in the available data sources.

For continuous variables (such as "target" cholesterol and blood pressure levels) a different strategy was adopted. MacMahon et al suggested that the relationship between diastolic blood pressure and the risk of a coronary event is linear and that each $2.5 \mathrm{~mm} \mathrm{Hg}$ reduction is associated with a $19 \%$ reduction in stroke and an $11 \%$ reduction in coronary events. ${ }^{30}$ We have estimated the relative reduction in events associated with achieving the GP contract targets of controlling blood pressure of $70 \%$ of patients with CHD, stroke, or hypertension to below the target of 150/90 $\mathrm{mm} \mathrm{Hg}$ and 55\% of patients with diabetes to below 145/85 mm Hg. To do this we estimated the benefit of reducing the diastolic blood pressure in all patients outside the target level in decrements of $2.5 \mathrm{~mm} \mathrm{Hg}$ until $70 \%$ of patients reached the target level. Once the diastolic blood pressure of an individual fell below the target level they did not participate in subsequent decrements. At each step we assumed that systolic blood pressure fell by $5 \mathrm{~mm} \mathrm{Hg}$ for each $2.5 \mathrm{~mm} \mathrm{Hg}$ reduction in diastolic blood pressure. ${ }^{30}$ We then estimated the average reduction in risk of $\mathrm{CHD}$ by summing the benefits from lowering blood pressure in all patients subject to one or more decrements. A similar strategy was adopted for the target to achieve a cholesterol level of $<5.0 \mathrm{mmol} / \mathrm{l}$ among $60 \%$ of people with CHD, stroke, and diabetes. We assumed that every $0.2 \mathrm{mmol} / \mathrm{l}$ decrement in cholesterol was associated with a reduction in risk of $10 \%$ for cardiovascular events. ${ }^{31} 32$

\section{Sensitivity analysis}

One way sensitivity analysis was performed by sequentially varying the estimates of aspirin uptake and the proportion of patients with CHD, stroke, and diabetes whose cholesterol reached the indicator target.

Using the methods described above we were able to estimate the health gain, expressed as numbers of adverse events prevented, for a range of interventions relating cardiovascular diseases in a hypothetical general practice population of 10000 in England and Wales.

\section{RESULTS}

\section{Prevalence of diseases}

Men are more likely to have CHD, stroke, diabetes, and CHD complicated by heart failure than women, particularly in the younger age group (table 2). There is also a marked increase in the prevalence of all diseases with age.

\section{Impact of cholesterol management targets}

In a nominal population of 10000 people and over a 5 year period, lowering total cholesterol in patients with recorded values above $5.0 \mathrm{mmol} / \mathrm{l}$ has the potential to prevent the 
Table 2 Age and sex specific prevalence of coronary heart disease, stroke, diabetes, hypertension, and coronary heart disease/heart failure in a 'standard' general practice population of 10000 patients

\begin{tabular}{|c|c|c|c|c|}
\hline \multirow[b]{2}{*}{ Disease } & \multicolumn{2}{|l|}{ Men } & \multicolumn{2}{|l|}{ Women } \\
\hline & $\begin{array}{l}\text { 45-64 years } \\
(n=1154)\end{array}$ & $\begin{array}{l}65-84 \text { years } \\
(n=384)\end{array}$ & $\begin{array}{l}\text { 45-64 years } \\
(n=1166)\end{array}$ & $\begin{array}{l}65-84 \text { years } \\
(n=440)\end{array}$ \\
\hline $\mathrm{CHD}^{9}$ & $8.4 \%$ & $21.5 \%$ & $3.8 \%$ & $14.6 \%$ \\
\hline Stroke & $2.1 \%$ & $7.8 \%$ & $1.4 \%$ & $6.1 \%$ \\
\hline Diabetes ${ }^{9}$ & $4.1 \%$ & $7.5 \%$ & $2.3 \%$ & $6.3 \%$ \\
\hline Hypertension ${ }^{9}$ & $18.8 \%$ & $19.7 \%$ & $19.0 \%$ & $29.5 \%$ \\
\hline $\mathrm{CHD}+\mathrm{HF}^{10} 11$ & $0.8 \%$ & $2.8 \%$ & $0.2 \%$ & $2.0 \%$ \\
\hline
\end{tabular}

greatest number of cardiovascular events (defined as angina pectoris, myocardial infarction, death from CHD, stroke, congestive heart failure, peripheral vascular disease, and death from cardiovascular disease). In particular, among people with $\mathrm{CHD}$, stroke and diabetes, the number of cardiovascular events that will be prevented by reaching the cholesterol management targets is 15.5, 7.2 and 6.5, respectively (tables 3 and 4).

\section{Impact of hypertension management targets}

Meeting the hypertension management targets will prevent 3.6, 2.9, and 2.9 events among people with CHD, stroke, and diabetes, respectively (tables 3 and 4 ). A further 15.5 events will be prevented by meeting the blood pressure targets in hypertensive patients without CHD, stroke, or diabetes.

\section{Impact of targets relating to aspirin, ACE inhibitors/ A2 antagonists, and influenza immunisation}

Aspirin is already widely used to treat patients with CHD and stroke, and patients with CHD complicated with heart failure are already likely to be receiving either an ACE inhibitor or an A2 antagonist. Achieving the quality indicator targets for these treatments will therefore only result in a small increase in their uptake and will only prevent a small number of events in these patient groups (tables 3 and 5). Due to the low baseline risk of deaths from influenza, despite the high relative risk reduction, the numbers of lives saved from increasing influenza immunisation is very small.

\section{Sensitivity analysis}

The above estimates for aspirin use are based on data from Northumberland. The data indicate that $81 \%$ of men with CHD aged 45-84 years are currently being treated with aspirin and therefore the incremental increase to achieve the targets is $9 \%$. This will result in the prevention of 0.74 events over the next 5 years. If, as reported elsewhere, ${ }^{33}$ only $64 \%$ of CHD patients are receiving aspirin treatment, then 2.17 events would be prevented over the same time period by achieving the GP contract targets. In general, for every $1 \%$ reduction in the proportion of CHD patients currently receiving aspirin therapy, the effect of achieving the aspirin targets of the GP contract will result in the prevention of approximately 0.083 more events.

Achieving the targets for cholesterol lowering may be difficult. The effect of achieving smaller reductions in cholesterol than specified in the targets can be estimated using the same methods. For example, if our notional practice achieves the contract target of getting $60 \%$ of CHD patients below $5.0 \mathrm{mmol} / \mathrm{l}$, based on cholesterol levels observed in the 1998 Health Survey we would expect this to prevent 6.4 events among women aged $45-84$. If a practice was only able to get $50 \%$ of this group of patients to achieve cholesterol levels below $5.0 \mathrm{mmol} / \mathrm{l}$, it could expect to prevent 5.8 events.

\section{DISCUSSION}

Meeting the 2003 GP contract quality targets for cardiovascular disease will prevent a quantifiable number of cardiovascular events over a 5 year period. The number of events prevented would be noticeable even in a practice with a population of around 10000 people. The greatest gains would come from meeting targets for cholesterol and blood pressure reduction. Smaller gains are likely to be achieved by meeting other targets, generally because the standard of care is already high and/or the prevalence of the condition is low. This also means that the population impact of achieving the

\begin{tabular}{|c|c|c|c|c|c|}
\hline \multirow[b]{2}{*}{ Intervention } & \multirow[b]{2}{*}{ Disease } & \multirow{2}{*}{$\begin{array}{l}\text { Target proposed in GP } \\
\text { contract }\end{array}$} & \multicolumn{2}{|c|}{$\begin{array}{l}\text { Estimate of level currently being } \\
\text { achieved }\end{array}$} & \multirow{2}{*}{$\begin{array}{l}\text { No of CVD events prevented } \\
\text { over } 5 \text { year period }\end{array}$} \\
\hline & & & 45-64 years & $65-84$ years & \\
\hline \multirow{3}{*}{$\begin{array}{l}\text { Cholesterol lowering } \\
\text { treatment }\end{array}$} & $\mathrm{CHD}$ & $60 \% \leqslant 5.0$ & $26 \%^{9}$ & $21 \%^{\circ}$ & 15.5 \\
\hline & Stroke & & $30 \%^{9}$ & $23 \%^{9}$ & 7.2 \\
\hline & Diabetes & & $30 \%^{9}$ & $30 \%^{\circ}$ & 6.5 \\
\hline \multirow{4}{*}{$\begin{array}{l}\text { Blood pressure lowering } \\
\text { treatment }\end{array}$} & CHD & $70 \% \leqslant 150 / 90$ & $76 \%^{9}$ & $60 \%^{\circ}$ & 3.6 \\
\hline & Stroke & $70 \% \leqslant 150 / 90$ & $72 \%^{9}$ & $49 \%^{9}$ & 2.9 \\
\hline & Diabetes & $55 \% \leqslant 145 / 85$ & $45 \%^{\circ}$ & $38 \%^{\circ}$ & 2.9 \\
\hline & Hypertension & $70 \% \leqslant 150 / 90$ & $56 \%^{\circ}$ & $32 \%^{9}$ & 15.5 \\
\hline \multirow[t]{2}{*}{ Aspirin } & CHD & $90 \%$ & $81 \%^{12}$ & $81 \%^{12}$ & 1.1 \\
\hline & Stroke & $90 \%$ & $81 \%^{12}$ & $81 \%^{12}$ & 0.4 \\
\hline $\begin{array}{l}\text { ACE inhibitors/A2 } \\
\text { antagonists }\end{array}$ & $\mathrm{CHD}$ and $\mathrm{HF}$ & $70 \%$ & $74 \%^{13}$ & $59 \%^{13}$ & 1.2 \\
\hline Influenza vaccination & CVD & $85 \%$ & $56 \%^{12}$ & $85 \%^{12}$ & $0.03^{*}$ \\
\hline
\end{tabular}

$\mathrm{CHD}=$ coronary heart disease; $\mathrm{ACE}=$ angiotensin converting enzyme; $\mathrm{A} 2=$ angiotensin $2 ; \mathrm{HF}=$ heart failure; $\mathrm{CVD}=$ cardiovascular disease . *Events prevented by influenza vaccination refer to influenza mortality and not cardiovascular events. 
Table 4 Coronary heart disease, stroke, diabetes and hypertension patients. Number of cardiovascular events prevented by improving control of blood pressure and cholesterol

\begin{tabular}{|c|c|c|c|c|c|}
\hline Condition/intervention & Sex & Age group & $\begin{array}{l}\text { Current } \% \text { of patients } \\
\text { within target level }\end{array}$ & $\begin{array}{l}\text { Baseline risk of } \\
\text { CVD event }\end{array}$ & $\begin{array}{l}\text { Reduction in number of } \\
\text { CVD events ( } \mathbf{n} \text { ) }\end{array}$ \\
\hline $\begin{array}{l}\mathrm{CHD} / \text { blood pressure lowering } \\
\text { treatment }\end{array}$ & $\begin{array}{l}M \\
F\end{array}$ & $\begin{array}{l}45-64 \\
65-84 \\
45-64 \\
65-84\end{array}$ & $\begin{array}{l}73 \% \\
62 \% \\
74 \% \\
59 \%\end{array}$ & $\begin{array}{r}12.8 \% \\
30.0 \% \\
6.6 \% \\
18.2 \%\end{array}$ & $\begin{array}{l}0.00 \\
2.37 \\
0.00 \\
1.21\end{array}$ \\
\hline $\begin{array}{l}\mathrm{CHD} / \text { cholesterol lowering } \\
\text { treatment }\end{array}$ & $\begin{array}{l}M \\
F\end{array}$ & $\begin{array}{l}45-64 \\
65-84 \\
45-64 \\
65-84\end{array}$ & $\begin{array}{l}25 \% \\
29 \% \\
21 \% \\
10 \%\end{array}$ & $\begin{array}{r}12.8 \% \\
30.0 \% \\
6.6 \% \\
18.2 \%\end{array}$ & $\begin{array}{l}3.20 \\
5.91 \\
0.88 \\
5.47\end{array}$ \\
\hline $\begin{array}{l}\text { Stroke/blood pressure lowering } \\
\text { treatment }\end{array}$ & $\begin{array}{l}M \\
F\end{array}$ & $\begin{array}{l}45-64 \\
65-84 \\
45-64 \\
65-84\end{array}$ & $\begin{array}{l}56 \% \\
49 \% \\
79 \% \\
51 \%\end{array}$ & $\begin{array}{r}17.0 \% \\
40.0 \% \\
8.8 \% \\
24.2 \%\end{array}$ & $\begin{array}{l}0.27 \\
1.54 \\
0.00 \\
1.08\end{array}$ \\
\hline $\begin{array}{l}\text { Stroke/cholesterol lowering } \\
\text { treatment }\end{array}$ & $\begin{array}{l}M \\
F\end{array}$ & $\begin{array}{l}45-64 \\
65-84 \\
45-64 \\
65-84\end{array}$ & $\begin{array}{l}26 \% \\
33 \% \\
27 \% \\
11 \%\end{array}$ & $\begin{array}{r}17.0 \% \\
40.0 \% \\
8.8 \% \\
24.2 \%\end{array}$ & $\begin{array}{l}1.25 \\
3.59 \\
0.44 \\
1.94\end{array}$ \\
\hline $\begin{array}{l}\text { Diabetes/blood pressure lowering } \\
\text { treatment }\end{array}$ & $\begin{array}{l}M \\
F\end{array}$ & $\begin{array}{l}45-64 \\
65-84 \\
45-64 \\
65-84\end{array}$ & $\begin{array}{l}43 \% \\
46 \% \\
48 \% \\
29 \%\end{array}$ & $\begin{array}{l}18.0 \% \\
28.6 \% \\
14.3 \% \\
23.5 \%\end{array}$ & $\begin{array}{l}0.55 \\
1.11 \\
0.27 \\
0.99\end{array}$ \\
\hline $\begin{array}{l}\text { Diabetes/cholesterol lowering } \\
\text { treatment }\end{array}$ & $\begin{array}{l}M \\
F\end{array}$ & $\begin{array}{l}45-64 \\
65-84 \\
45-64 \\
65-84\end{array}$ & $\begin{array}{l}32 \% \\
45 \% \\
20 \% \\
17 \%\end{array}$ & $\begin{array}{l}18.0 \% \\
28.6 \% \\
14.3 \% \\
23.5 \%\end{array}$ & $\begin{array}{l}2.09 \\
1.95 \\
0.94 \\
1.54\end{array}$ \\
\hline $\begin{array}{l}\text { Hypertension/blood pressure } \\
\text { lowering treatment }\end{array}$ & $\begin{array}{l}M \\
F\end{array}$ & $\begin{array}{l}45-64 \\
65-84 \\
45-64 \\
65-84\end{array}$ & $\begin{array}{l}54 \% \\
29 \% \\
58 \% \\
34 \%\end{array}$ & $\begin{array}{r}10.6 \% \\
21.0 \% \\
6.3 \% \\
13.1 \%\end{array}$ & $\begin{array}{l}5.00 \\
3.40 \\
2.41 \\
4.64\end{array}$ \\
\hline
\end{tabular}

quality indicator targets will be less at practices already achieving high levels of treatment and control of cardiovascular risk factors. Due to the high baseline risk among those aged 85 or more, our exclusion of this age group underestimates the potential population benefit. Had we felt able to include these groups, there looked to be significant additional health gains in the very elderly.

We have examined outcome measures of cardiovascular disease because it is relatively simple to obtain information to allow calculations to be made. A number of components of the proposed GP contract cannot be quantified in this way due either to lack of effectiveness evidence or uncertainty that they will directly lead to quantifiable health gain. For example, we have not addressed other potential sources of health gain such as reducing the prevalence of smoking. This is because it is difficult to link the quality indicators of recording smoking status and offering smoking cessation advice to specific reductions in smoking prevalence. Also, to

Table 5 Coronary heart disease, stroke and coronary heart disease/heart failure patients. Number of cardiovascular events prevented by increasing uptake of aspirin, ACE inhibitors/A2 antagonists and influenza immunisation

\begin{tabular}{|c|c|c|c|c|c|c|}
\hline $\begin{array}{l}\text { Condition } \\
\text { (intervention) }\end{array}$ & Sex & Age group & $\begin{array}{l}\text { Current } \\
\text { treatment level }\end{array}$ & $\begin{array}{l}\text { Incremental increase in } \\
\text { treatment in those not } \\
\text { contraindicated (peinc) }\end{array}$ & $\begin{array}{l}5 \text { year baseline risk of } \\
\text { CVD event (P) }\end{array}$ & NEPP for CVD events \\
\hline \multirow[t]{3}{*}{ CHD (aspirin) } & $M$ & $\begin{array}{l}45-64 \\
65-84\end{array}$ & $\begin{array}{l}81 \% \\
81 \%\end{array}$ & $\begin{array}{l}9 \% \\
9 \%\end{array}$ & $\begin{array}{l}12.8 \% \\
30.0 \%\end{array}$ & $\begin{array}{l}0.25 \\
0.49\end{array}$ \\
\hline & $\mathrm{F}$ & $45-64$ & $80 \%$ & $10 \%$ & $6.6 \%$ & 0.07 \\
\hline & & $65-84$ & $80 \%$ & $10 \%$ & $18.2 \%$ & 0.26 \\
\hline \multirow{4}{*}{ Stroke (aspirin) } & M & $45-64$ & $81 \%$ & $9 \%$ & $17.0 \%$ & 0.07 \\
\hline & & $65-84$ & $81 \%$ & $9 \%$ & $40.0 \%$ & 0.21 \\
\hline & $\mathrm{F}$ & $45-64$ & $80 \%$ & $10 \%$ & $8.8 \%$ & 0.03 \\
\hline & & $65-84$ & $80 \%$ & $10 \%$ & $24.2 \%$ & 0.13 \\
\hline $\mathrm{CHD} / \mathrm{HF}$ (ACE & M & $45-64$ & $80 \%$ & $0 \%$ & $29.8 \%$ & 0.00 \\
\hline inhibitors/A2 & & $65-84$ & $64 \%$ & $6 \%$ & $70 \%$ & 0.44 \\
\hline \multirow[t]{2}{*}{ antagonists } & $\mathrm{F}$ & $45-64$ & $60 \%$ & $10 \%$ & $15.4 \%$ & 0.09 \\
\hline & & $65-84$ & $52 \%$ & $18 \%$ & $42.4 \%$ & 0.66 \\
\hline \multirow{4}{*}{$\begin{array}{l}\text { CDD (intluenza } \\
\text { immunisation) }\end{array}$} & M & $45-64$ & $55 \%$ & $30 \%$ & $0.1 \%$ & 0.02 \\
\hline & & $65-84$ & $85 \%$ & $0 \%$ & $1.2 \%$ & 0.00 \\
\hline & $\mathrm{F}$ & $45-64$ & $58 \%$ & $27 \%$ & $0.1 \%$ & 0.01 \\
\hline & & $65-84$ & $84 \%$ & $1 \%$ & $1.2 \%$ & 0.00 \\
\hline
\end{tabular}

$\mathrm{CHD}=$ coronary heart disease $; \mathrm{CVD}=$ cardiovascular disease; $\mathrm{ACE}=$ angiotensin converting enzyme; $\mathrm{A} 2=$ angiotensin $2 ; \mathrm{NEPP}=$ number of events prevented in population. 


\section{Key messages}

- Population impact measures can help to estimate health gains from achieving quality of care targets.

- Achievement of the quality indicators relating to the management of cardiovascular diseases included in the new UK general practitioner contract will result in significant health gains.

- For a notional practice population of 10000 , the greatest health gain in those aged $45-84$ years would come from reaching targets for cholesterol reduction and blood pressure control.

- Achieving other cardiovascular disease targets would have a much smaller impact.

- The cost effectiveness of these interventions has yet to be measured.

judge the impact for cardiovascular events alone does not take into account the much wider health gain expected from smoking cessation.

Another limitation is that we have not addressed harms that may result from achievement of the quality indicatorsfor example, the side effects from additional drug treatments. We have also not examined the role of patient adherence with treatment. Our modelling assumes continuous optimal compliance with prescribed treatment. This is unlikely to be realistic as some patients may not be able to adhere to treatment, or may decide themselves that treatment for the management of some of the reviewed conditions is not worthwhile. As a result, we may have overestimated the population health benefit. If compliance with a particular treatment among those who had no contraindication was only $80 \%$, the expected impact of that treatment would be to prevent $80 \%$ of the events estimated under the assumption of $100 \%$ compliance.

We have not attempted to quantify the opportunity cost or resources required to achieve improvements in care for the conditions examined here. For example, other aspects of care may suffer, resulting in negative health gain if practice effort is disproportionately directed towards the targets associated with financial incentives. Additionally, the cost effectiveness of different interventions suggested in the GP contract has not yet been determined-for example, optimising the management of hypertension might or might not be more cost effective than optimising the management of cholesterol in patients with CHD, stroke, and diabetes. Small increases in aspirin prescribing, although of limited population impact, may still be highly cost effective as aspirin is so cheap compared with other treatments. Further research on cost effectiveness will be welcome and can be informed by the assessment of population impact. ${ }^{28}$

We have not provided confidence intervals for our estimates. The calculations involve a large number of components that are subject to variation and calculating the confidence intervals would be difficult. However, many of the components of the calculations are constants within a practice. At a given point in time, a practice will have a fixed number of patients with a given disease and a fixed percentage or patients who are treated. Therefore, provided valid data are available, a general practice could estimate the effect in their setting more accurately by adjusting our estimates up or down according to current practice treatment levels and disease prevalence. This underlines the importance of the collection of timely and valid local data.
The traditional epidemiological measures of the effect of an intervention-the relative risk reduction-does not give a clear indication of the impact of an intervention at the population level as it does not take into account the baseline risk. Individually based measures that do take this into account (such as numbers needed to treat) are less useful for assessing priorities and impact at the population level because they do not take into account the prevalence of the condition and proportion eligible for an intervention.

The NEPP is a relatively simple measure which estimates the true population estimate of an intervention and can be applied to a notional or real population. Decision makers within practices and PCTs can use these measures to estimate the extra health benefit of meeting the particular targets identified in the contract. Although our absolute estimates relate to a general practice population of 10000 with the age and sex distribution of England and Wales, the order of the impact of the interventions examined is likely to be similar in other populations.

This method could be used to revise the targets on the basis of their likely impact on the population of patients seen in a general practice, and to identify areas where future changes to the quality and outcomes framework would be likely to produce the greatest health gain. Practitioners could use these results to prioritise the order in which they tackle improvements in care to maximise the benefit to their population. We are nevertheless conscious that population impact should not be seen as the only determinant of priorities, as some highly effective interventions relate to conditions of very low prevalence (such as screening for congenital metabolic disorders) and hence have low population impact.

In conclusion, we have shown that, using population impact measures, it is possible to quantify the health gain to a practice population from improving care in line with achieving the quality indicator targets set in the new GP contract. The gain is sensitive to the quality of care currently being provided, the size of the anticipated change in treatment, and the prevalence of the condition or risk factor. The method we have described allows a practice to estimate and demonstrate the benefit to their population of meeting the targets in the GP contract (or other targets) and is a way of showing that such targets, if achieved, will result in quantifiable health gain. Future revisions to the contract could take into account estimates of population health gain.

\section{Authors' affiliations}

P McElduff, G Lyratzopoulos, R Edwards, R F Heller, Evidence for Population Health Unit, School of Epidemiology and Health Sciences, Medical School, University of Manchester, Manchester, UK

P Shekelle, Greater Los Angeles VA Healthcare System, Los Angeles, California, USA

M Roland, National Primary Care Research and Development Centre, University of Manchester, Manchester, UK

\section{REFERENCES}

1 Department of Health. General Medical Services Contract. Annex A: Quality Indicators, http://www.doh.gov.uk/gmscontract/annexaquality.pdf (last accessed December 2003).

2 Australian General Practice Accreditation Limited. www.agpal.com.au (last accessed Jan 5 2004).

3 Practice Incentives Programme. An outline of the Practice Incentives Programme. http://www.hic.gov.au/providers/resources/ incentives_allowances/pip/outline_pip_whole.pdf (last accessed Jan 5 2004).

4 Seddon ME, Marshall MN, Campbell SM, et al. Systematic review of quality of clinical care in general practice in the UK, Australia and New Zealand. Qual Health Care $2001 ; 10: 152-8$.

5 Campbell SM, Hann M, Hacker J, et al. Identifying predictors of high quality care in English general practice: observational study. BMJ 2001;323:784-7.

6 Chaix-Couturier C, Durand-Zaleski I, Jolly D, et al. Effects of financial incentives on medical practice: results from a systematic review of the literature and methodological issues. Int J Qual Health Care 2000;12:133-42. 
7 Gosden T, Forland F, Kristiansen IS, et al. Impact of payment method on behaviour of primary care physicians: a systematic review. J Health Serv Res Policy $2001 ; 6: 44-55$.

8 Edwards R, Burns JA, McElduff P, et al. Variations in process and outcomes of diabetes care by socio-economic status in Salford, UK. Diabetologia 2003:6:750-9

9 Department of Health. Health survey for England 1998: cardiovascular disease. London: Stationery Office, 1999. http://www.doh.gov.uk/public/ hse98.htm (accessed 5 Jan 2004).

10 Davies MK, Hobbs FDR, Davis RC, et al. Prevalence of left-ventricular systolic dysfunction and heart failure in the Echocardiographic Heart of England Screening study: a population based survey. Lancet 2001;358:439-44.

11 Fox KF, Cowie MR, Wood DA, et al. Coronary artery disease as the cause of incident heart failure in the population. Eur Heart J 2001;22:228-36.

12 Edwards R, Murphy P, Allan K, et al. Comparative morbidity data in primary care: the Northumberland MEDICS project. Primary Health Care Res Devel 2002;3:217-27.

13 Ellis C, Gnani S, Majeed A. Prevalence and management of heart failure in general practice in England and Wales 1994-1998. Health Stat $Q$ 2001;11:17-24.

14 Stockport NHS Trust. Department of Epidemiology. Health care for patients with HF: Evaluation Report. 2002.

15 Anderson KM, Odell PM, Wilson PWF, et al. Cardovascular disease risk profiles. Am Heart J 1991:121:293-8.

16 Thompson WW, Shay DK, Weintraub E, et al. Mortality associated with influenza and respiratory syncitial virus in the United States. JAMA 2003;289:179-86.

17 Sprenger MJ, Mulder PG, Beyer WE, et al. Impact of influenza on mortality in relation to age and underlying disease, 1967-1989. Int J Epidemiol 1993;22:334-40.

18 Nordin J, Mullooly J, Poblete S, et al. Influenza vaccine effectiveness in preventing hospitalisation and deaths in persons 65 years and older in Minnesota, New York and Oregon: data from 3 health plans. J Infect Dis $2001 ; 184: 665-70$

19 Hak E, Verheij TJ, van Esen GA, et al. Prognostic factors for influenzaassociated hospitalisation and death during an epidemic. Epidemiol Infect 2001; 126:261-8.

20 Flemming DM, Watson JM, Nicholas $S$, et al. Study of the effectiveness of influenza vaccination in the elderly in the epidemic of 1989-90 using a general practice database. Epidemiol Infect 1995;115:581-9.
21 Sharma D, Buyse M, Pitt B et al. The Losartan heart failure mortality metaanalysis study group. Meta-analysis of observed mortality data from allcontrolled, double blind, multiple dose studies of Losartan in heart failure. Am J Cardiol 2000;85:187-92.

22 Brophy JM, Joseph L, Rouleau JL. Beta-blockers in congestive heart failure. Ann Intern Med 2001;134:550-60.

23 Pitt B, Zanad F, Remme WJ, et al. The effect of spironolactone on moridity and mortality in patients with severe heart failure. N Engl J Med 1999;341:709-17.

24 The SOLVD investigator. Effect of enalapril on survival in patients with reduced left ventricular ejection fractions and congestive heart failure. N Engl J Med 1991;325:293-302.

25 McAlister FA. Commentary: Relative treatment effects are consistent across the spectrum of underlying risks... usually. Int J Epidemiol 2002;31:76-7.

26 Furukawa TA, Guyatt GH, Griffith LE. Can we individualize the "number needed to treat"? An empirical study of summary effect measures in metaanalyses. Int J Epidemiol 2002;31:72-8.

27 Vu T, Farish S, Jenkins $M$, et al. A meta-analysis of influenza vaccine in persons aged 65 years and older living in the community. Vaccine 2002;20:1831-6.

28 Heller RF, Edwards R, McElduff P. Implementing guidelines in primary care: can population impact measures help? BMC Public Health 2003;3:7.

29 Department of Health. Compendium of clinical and health indicators. London: Department of Health, 2000.

30 MacMahon S, Peto R, Cutler J, et al. Blood pressure, stroke, and coronary heart disease. Part 1, prolonged differences in blood pressure: prospective observational studies corrected for the regression dilution bias. Lancet 1990;335:765-74.

31 Law MR, Wald NJ, Wu T, et al. Systematic underestimation of association between serum cholesterol concentration and ischaemic heart disease in observational studies: data from the BUPA study. BMJ 1994;308:363-6.

32 Law MR, Wald NJ, Thompson SG. By how much and how quickly does reduction in serum cholesterol concentration lower risk of ischaemic hear disease? BMJ 1994;308:367-73.

33 Carrol K, Majeed A, Firth C, et al. Prevalence and management of coronary heart disease in primary care: population-based cross-sectional study using a disease register. J Publ Health Med 2003;25:29-35.

34 Antithrombotic Trialists' Collaboration. Collaborative meta-analysis of randomised trials of antiplatelet therapy for prevention of death myocardial infarction, and stroke in high risk patients. BMJ 2002;324:71-86. 